\title{
Placental endoplasmic reticulum stress in gestational diabetes: the potential for therapeutic intervention with chemical chaperones and antioxidants
}

\author{
Hong-wa Yung ${ }^{1}$ - Patji Alnæs-Katjavivi ${ }^{2}$ - Carolyn J. P. Jones ${ }^{3}$. Tatiana El-Bacha ${ }^{4}$. \\ Michaela Golic ${ }^{5,6,7}$ • Anne-Cathrine Staff ${ }^{2}$ • Graham J. Burton ${ }^{1}$
}

Received: 5 May 2016 / Accepted: 10 June 2016/Published online: 12 July 2016

(C) The Author(s) 2016. This article is published with open access at Springerlink.com

\begin{abstract}
Aims/hypothesis The aim of this work was to determine whether placental endoplasmic reticulum (ER) stress may contribute to the pathophysiology of gestational diabetes mellitus (GDM) and to test the efficacy of chemical chaperones and antioxidant vitamins in ameliorating that stress in a trophoblast-like cell line in vitro.

Methods Placental samples were obtained from women suffering from GDM and from normoglycaemic controls and were frozen immediately. Women with GDM had $2 \mathrm{~h}$ serum glucose levels $>9.0 \mathrm{mmol} / \mathrm{l}$ following a $75 \mathrm{~g}$ oral glucose
\end{abstract}

Electronic supplementary material The online version of this article (doi:10.1007/s00125-016-4040-2) contains peer-reviewed but unedited supplementary material, which is available to authorised users.

Graham J. Burton

gjb2@cam.ac.uk

1 Centre for Trophoblast Research, Department of Physiology, Development and Neuroscience, Physiological Laboratory, University of Cambridge, Downing Street, Cambridge CB2 3EG, UK

2 Department of Obstetrics and Gynecology, Oslo University Hospital, Ullevål and Faculty of Medicine, University of Oslo, Oslo, Norway

3 Centre for Maternal and Fetal Health, Institute of Human Development, University of Manchester, Manchester, UK

4 Institute of Nutrition, Federal University of Rio de Janeiro, Rio de Janeiro, Brazil

5 Experimental and Clinical Research Center, a cooperation between the Max Delbrück Center for Molecular Medicine in the Helmholtz Association and the Charité-Universitätsmedizin Berlin, Berlin, Germany

6 Department of Obstetrics and Gynecology, CharitéUniversitätsmedizin Berlin, Berlin, Germany

7 Berlin Institute of Health (BIH), Berlin, Germany tolerance test and were treated with diet and insulin when necessary. Western blotting was used to assess markers of ER stress. To test the effects of hyperglycaemia on the generation of ER stress, a new trophoblast-like cell line, BeWo-NG, was generated by culturing in a physiological glucose concentration of $5.5 \mathrm{mmol} / \mathrm{l}$ (over 20 passages) before challenging with 10 or $20 \mathrm{mmol} / \mathrm{l}$ glucose.

Results All GDM patients were well-controlled $\left(\mathrm{HbA}_{1 \mathrm{c}} 5.86\right.$ $\pm 0.55 \%$ or $40.64 \pm 5.85 \mathrm{mmol} / \mathrm{mol}, n=11)$. Low-grade ER stress was observed in the placental samples, with dilation of ER cisternae and increased phosphorylation of eukaryotic initiation factor 2 subunit $\alpha$. Challenge of BeWo-NG with high glucose activated the same pathways, but this was as a result of acidosis of the culture medium rather than the glucose concentration per se. Addition of chemical chaperones 4phenylbutyrate and tauroursodeoxycholic acid and vitamins $\mathrm{C}$ and $\mathrm{E}$ ameliorated the ER stress.

Conclusions/interpretation This is the first report of placental ER stress in GDM patients. Chemical chaperones and antioxidant vitamins represent potential therapeutic interventions for GDM.

Keywords Antioxidants $\cdot$ Chaperones $\cdot$ Endoplasmic reticulum stress - Gestational diabetes $\cdot$ Metabolic acidosis . Placenta $\cdot$ Trophoblast $\cdot$ Unfolded protein response

$\begin{array}{ll}\text { Abbreviations } \\ \text { ATF6 } & \text { Activating transcription factor } 6 \\ \text { eIF2 } \alpha & \text { Eukaryotic initiation factor } 2 \text { subunit } \alpha \\ \text { ER } & \text { Endoplasmic reticulum } \\ \text { GDM } & \text { Gestational diabetes mellitus } \\ \text { GRP } & \text { Glucose regulated protein } \\ \text { hPGH } & \text { Human placental growth hormone } \\ \text { hPL } & \text { Human placental lactogen }\end{array}$




$\begin{array}{ll}\text { IRE1 } & \text { Inositol-requiring enzyme 1 } \\ \text { JNK } & \text { c-Jun N-terminal kinase } \\ \text { 4-PBA } & \text { 4-Phenylbutyrate } \\ \text { PDI } & \text { Protein disulfide isomerase } \\ \text { PERK } & \text { Protein kinase RNA-like ER kinase } \\ \text { TUDCA } & \text { Tauroursodeoxycholic acid } \\ \text { UPR } & \text { Unfolded protein response } \\ \text { XBP-1 } & \text { X-box binding protein 1 }\end{array}$

\section{Introduction}

Gestational diabetes mellitus (GDM) is a subtype of diabetes that arises de novo late in the second trimester or early in the third trimester of pregnancy. It represents a global health challenge, with incidences reaching $17.8 \%$ of total pregnancies [1]. Predisposing factors include maternal obesity, metabolic dysfunction and genetic susceptibility. Although the mechanisms are not fully understood, decreased insulin sensitivity and inadequate insulin secretion are two common causative factors. Women with GDM are at increased risk of developing other complications of pregnancy, including pregnancy-induced hypertension and pre-eclampsia [2]. They also have an increased lifetime risk for type 2 diabetes of approximately $30 \%$ [3]. For the fetus, GDM poses an increased risk of stillbirth, perinatal complications, macrosomia and growth restriction [4], and there is a greater predisposition to type 2 diabetes, obesity and metabolic and cardiovascular diseases later in life $[5,6]$.

Pregnancy is a pro-diabetogenic state due to changes in the endocrine regulation of maternal carbohydrate and lipid metabolism, which are essential for elevating circulating blood glucose to meet fetal demands. Consequently, maternal organs and peripheral tissues are adapted for glucose intolerance and insulin resistance. As pregnancy advances, the placenta is the major driver of these maternal metabolic adaptations [7]. Although widely recognised as an organ of nutrient and gaseous exchange, the placenta secretes an array of polypeptide hormones, growth factors, cytokines and adipokines that modulate maternal metabolism and fetal growth. Human placental lactogen (hPL) and prolactin induce beta cell expansion and insulin release in the maternal pancreas [8], while human placental growth hormone (hPGH) and adipokines cause peripheral insulin resistance [9]. Maternal serum concentrations of hPL and hPGH increase up to 30- and eightfold, respectively, during pregnancy [10]. The placenta also secretes leptin, regulated by a placenta-specific upstream enhancer [11], and adiponectin [12] for regulation of maternal lipid metabolism, favouring fatty acids as a fuel source in maternal tissues. In normal pregnancy, these factors act in concert to redistribute maternal energy resources, increasing their availability for the fetus. However, perturbation of placental function potentially disrupts their bioactivity, altering the normal balance of maternal metabolism and resulting in GDM.

Organs with high polypeptide endocrine activity, such as the pancreas and placenta, are susceptible to endoplasmic reticulum (ER) stress. The ER coordinates the biosynthesis and post-translational modification of secreted proteins and membrane receptors, as well as maintaining calcium homoeostasis in cells. Therefore, any perturbation of the ER intraluminal environment can severely affect the bioactivity of secreted proteins. Accumulation of misfolded proteins in the ER provokes activation of an integrated network of signalling pathways known as the unfolded protein response (UPR). These pathways aim to restore ER homeostasis and involve protein kinase RNA-like ER kinase (PERK)-eukaryotic initiation factor 2 subunit $\alpha$ (eIF2 $\alpha$ ), which attenuates non-essential protein synthesis, and ATF6 (activating transcription factor 6) and inositol-requiring enzyme 1 (IRE1)-X-box binding protein 1 (XBP-1), which promote the synthesis of ER-resident chaperones to increase folding capacity. If these pathways fail to restore homeostasis, apoptosis is activated to eliminate the damaged cells [13].

Research on the role of ER stress in human diabetes has advanced rapidly and targeting to ameliorate ER stress has become a therapeutic intervention [14]. In type 2 diabetes, ER stress-induced dysfunction of pancreatic beta cells reduces insulin production as well as its bioactivity, resulting in hyperglycaemia [15]. The current view is that GDM is a pre-diabetic state and, although there may be several underlying causes, the majority of cases appear to be due to pre-existing low-grade chronic beta cell dysfunction [16]. Consequently, insufficient insulin is secreted to overcome the pregnancy-induced insulin resistance in the maternal organs/peripheral tissues [17].

We have demonstrated the central role of placental ER stress in the pathophysiology of pregnancy complications, including fetal growth restriction and early-onset pre-eclampsia $[18,19]$. In this study, we first investigate evidence of ER stress in placentas from women with GDM. We then use an in vitro trophoblastic-like cell model to elucidate the mechanisms by which hyperglycaemia may induce placental ER stress. Finally, we examine the ability of chemical chaperones and antioxidants to mitigate ER stress in trophoblast-like cells under high glucose concentrations.

\section{Methods}

Materials All chemicals were purchased from either Sigma-Aldrich (Dorset, UK) or Fisher Scientific UK (Loughborough, UK) except where otherwise stated. Antibodies against p-eIF $2 \alpha$ (Ser51), eIF $2 \alpha$, calreticulin and protein disulphide isomerase (PDI) were from Cell Signalling Technology (NEB, Hitchin, UK). Antibodies against XBP-1 
and glucose related protein (GRP) 94 were from Abcam (Cambridge, UK), anti-Desmoplakin 1/2 was from AbD Serotec (Oxford, UK), anti-GRP78 was from Transduction Laboratories (BD Biosciences, Oxford, UK), and anti- $\beta$-actin was from Sigma-Aldrich. All antibodies were used according to manufacturer's instruction except where otherwise stated.

\section{Participant selection and placental tissue collection} Placental samples were obtained from Oslo Pregnancy Biobank at Oslo University Hospital, Norway (www.oslouniversitetssykehus.no/opb). Twenty-one placentas from singleton pregnancies were delivered by non-laboured elective Caesarean section. The study was approved by the South-Eastern Norway Regional Committee for Medical and Health Research Ethics and informed consent was obtained from all participants.

Pregnant women with ( $n=11)$ and without $(n=10)$ GDM were originally recruited onto the study. GDM participants had $2 \mathrm{~h}$ serum glucose levels $>9.0 \mathrm{mmol} / \mathrm{l}$ following a $75 \mathrm{~g}$ oral glucose tolerance test. GDM participants were treated by diet, and insulin was started if necessary, based on clinical indication. The control group ('Control 1') was free from pre- and post-gestational diseases (including chronic diseases and pregnancy complications), and had healthy pregnancy outcomes. Thirty per cent of individuals in Control 1 had a pre-gestational $\mathrm{BMI}>25$. A second control group ('Control 2 '; $n=8$ ) was also recruited for comparison with normoglycaemic individuals with overweight/obesity $(n=7)$. All participants in Control 2 had a pre-gestational BMI $<25$ and, as with Control 1, were free from pre- and postgestational diseases and had healthy pregnancy outcomes.

$\mathrm{HbA}_{1 \mathrm{c}}$ measurements were performed at standardised intervals during the participant's pregnancy, in keeping with the institution's guidelines for antenatal follow-up of diabetes in pregnancy. Capillary samples were collected from participants using Accu-chek Safe-T-pro Plus lancets (Roche Diagnostics, Indianapolis, IN, USA) and added to a reagent kit for whole blood (DCA Systems Hemoglobin $A_{1 c}$ Reagent Kit, Siemens Healthcare Diagnostics, Tarrytown, NY, USA). The $\mathrm{HbA}_{1 \mathrm{c}}$ concentration was analysed in the clinic ('at point of care') using the Siemens/Bayer DCA 2000+ Analyzer from 2001-2013 (replaced by Siemens DCA Vantage Analyzer as of 2014 [Global Division, Siemens Healthcare Diagnostics, Tarrytown, NY, USA; see www.siemens.com/diagnostics]). To convert values for $\mathrm{HbA}_{1 \mathrm{c}}$ in \% (National Glycohemoglobin Standardization Program [NGSP] units) into $\mathrm{mmol} / \mathrm{mol}$ (International Federation of Clinical Chemistry and Laboratory Medicine [IFCC] units), subtract 2.15 and multiply by 10.929 .

In all participants, gestational age was determined during pregnancy by ultrasound scanning between 17 and 20 weeks of gestation and all participants delivered at the same gestational stage. Placental samples were processed immediately following delivery. Biopsies were selected from a macroscopically normal-looking, centrally located lobule, avoiding the decidual and membrane layers. Samples were snap-frozen in liquid nitrogen and stored at $-80^{\circ} \mathrm{C}$. All samples were analysed on a non-blinded basis.

Generation of a new line of BeWo cells, BeWo-NG BeWo cells were a gift from Professor Charnock-Jones (Department of Obstetrics and Gynaecology, University of Cambridge, UK) and were verified using a panel of markers for trophoblast cells [20]. They were not tested for Mycoplasma contamination. BeWo cells are routinely cultured in medium with a high concentration of glucose, such as DMEM/F12 (containing $17.1 \mathrm{mmol} / \mathrm{l}$ glucose). This non-physiological hyperglycaemic environment renders these cells inappropriate for any glucoserelated study. Therefore, a new line, BeWo-NG, was generated by culturing cells in the physiological glucose concentration of $5.5 \mathrm{mmol} / \mathrm{l}$ in modified DMEM/F12 medium, which was prepared by adding $0.99 \mathrm{~g}$ of glucose into 11 of glucose-free DMEM/F12 medium (US Biological, Salem, MA, USA). Details are described in the ESM Methods; 'Generation of new line of BeWo cells, BeWo-NG and culturing conditions'. After 20 passages, the BeWo-NG cells showed no difference in proliferation rate compared with parental BeWo cells (ESM Fig. 1a). Treatment with $10 \mu \mathrm{mol} / 1$ forskolin A induced syncytialisation as indicated by loss of Desmoplakin staining using anti-human Desmoplakin 1/2 antibody (AbD Serotec, Oxford, UK) and production of human chorionic gonadotrophin (ESM Fig. 1b, c). Details of Desmoplakin 1/2 immunocytochemical staining are described in ESM. These results confirmed that the BeWo-NG cells retained properties similar to those of the parental BeWo cells.

Western blot analysis The levels of total and phosphorylated proteins and kinases were measured by western blotting as described in the ESM Methods. All antibodies were used at a 1:1000 dilution except GRP78 and $\beta$-actin, which were used at a 1:10,000 dilution. All primary antibodies were diluted in Tris-buffered saline (TBS) containing $0.1 \%$ (vol./vol.) Tween 20 and incubated overnight at $4{ }^{\circ} \mathrm{C}$, followed by a few hours at room temperature. The antibodies for ER and oxidative stress markers were validated with cell lysates prepared from the cells treated with either ER stress inducers (tunicamycin [Sigma-Aldrich] and thapsigargin [Sigma-Aldrich]) or exposure to repetitive hypoxia-reoxygenation, as shown in previous publications [18, 24].

Measurement of $\mathbf{p H}$ The $\mathrm{pH}$ of media was determined using a pH meter (JENCO model 60, Lazar Research Laboratories, Los Angeles, CA, USA) connected to a micro $\mathrm{pH}$ electrode (Lazar Research Laboratories). Each experimental condition was performed in duplicate. 
Lactate assay Lactate accumulation in the culture media was evaluated enzymatically in hydrazine/glycine buffer ( $\mathrm{pH} 9.2$ ), containing $5 \mathrm{mg} / \mathrm{ml} \beta-\mathrm{NAD}^{+}$and $30 \mathrm{U} / \mathrm{ml}$ lactate dehydrogenase to a final volume of $1 \mathrm{ml}$ [21]. The reaction was started by addition of a sample. The change in absorbance because of NADH formation was monitored for $4 \mathrm{~min}$ at $340 \mathrm{~nm}$ using a Helios $\alpha$ UV-VIS spectrophotometer (Unicam, Cambridge, UK). A lactate calibration curve ranging from 10 to $150 \mu \mathrm{mol} / \mathrm{l}$ was constructed and used to calculate lactate concentrations in samples.

Electron microscopy Samples from normal and GDM placentas were fixed immediately after delivery in $2.5 \%$ glutaraldehyde (wt/vol.) in $0.1 \mathrm{~mol} / \mathrm{l}$ cacodylate buffer for $4 \mathrm{~h}$, post-fixed in $1 \%$ osmium and then embedded in Araldite resin. Thin sections were stained with lead citrate and uranyl acetate, and viewed using a Philips CM100 microscope (FEI, Hillsboro, OR, USA). All chemicals were purchased from TAAB Laboratories Equipment (Berks, UK)

Statistical analysis Statistical analyses were performed in GraphPad Prism 6.0 (GraphPad Software, La Jolla, CA, USA). Differences were tested using the non-parametric Mann-Whitney $U$ test or parametric Student's $t$ test, with $p<0.05$ being considered significant. For multiple comparisons, differences were tested using non-parametric KruskalWallis test, followed by Dunn's multiple comparisons test.

\section{Results}

The GDM and control groups were similar regarding gestational age at delivery and maternal age (Table 1). Pre-pregnancy and delivery maternal BMI, were significantly higher in the GDM group than in the control group, whereas birthweights and placental weights were not significantly different. All GDM patients showed elevated levels of $\mathrm{HbA}_{1 \mathrm{c}}$ $(5.86 \pm 0.55 \%$ or $40.64 \pm 5.85 \mathrm{mmol} / \mathrm{mol}, n=11)$, indicating chronic hyperglycaemia. Although the $\mathrm{HbA}_{1 \mathrm{c}}$ level was not measured in the control group, a previous study reported a value of approximately $5 \%$ or $31 \mathrm{mmol} / \mathrm{mol}$ in the third trimester of normal pregnancy [22].

\section{Low-grade ER stress is increased in GDM placentas} Electron microscopy revealed mild to moderate dilatation of the ER cisternae, a hallmark of ER stress, in the syncytiotrophoblast of placentas from GDM pregnancies compared with normoglycaemic controls (Fig. 1a). The normal ER cisternae and mitochondrial cristae in the cytotrophoblast and endothelial cells confirmed that these appearances were not fixation artefacts (Fig. 1a).

To assess the severity of ER stress in the GDM placentas, the activity of the PERK, ATF6 and IRE1 pathways was monitored by examining their corresponding downstream effectors. Results revealed an increase of $>8$ in phosphorylation of eIF $2 \alpha$ (p-eIF $2 \alpha$; Fig. 1 b, c), but no evidence of splicing of $X B P-1$. There was, however, a $\sim 1.2$-fold elevation of the fulllength XBP-1(FL) protein translated from the unspliced $X B P$ 1 mRNA. The correlation between levels of $\mathrm{p}$-eIF $2 \alpha$ and $\mathrm{HbA}_{1 \mathrm{c}}$ did not reach statistical significance ( $\mathrm{p}$-eIF $2 \alpha$, $p=0.079$, Fig. 1d). ATF6 is processed by specific proteases to generate a potent ATF6(p50) transcription factor [16]. Although the ATF6 $\alpha$ antibody used recognises both the fulllength ATF $\alpha \alpha(\mathrm{p} 90)$ and the active form (ATF6 $\alpha[\mathrm{p} 50])$ only the active form was detected (Fig. 1c). The level of ATF6 $\alpha(\mathrm{p} 50)$ in the GDM placentas showed no significant difference $(p=0.09)$ compared with control placentas. Furthermore, the downstream targets of ATF6 $\alpha(\mathrm{p} 50)$, GRP78 and GRP94, were unchanged compared with the controls. To summarise, both ultrastructural analysis and ER molecular markers demonstrate the existence of mild ER stress in placentas from GDM pregnancies.

Women with GDM had a pre-pregnancy BMI significantly higher than that of women in the control group, Control 1 (Table 1). Therefore, we investigated the contribution of obesity in the activation of placental ER stress. To allow for comparison with a solely non-obese control group, a second control group comprising placentas from non-obese women (BMI <25) with normal pregnancies (Control 2) was also collected. The prepregnancy BMI of the overweight/obese women was significantly higher than that of Control $2\left(29 \pm 1\right.$ vs $21 \pm 0.2 \mathrm{~kg} / \mathrm{m}^{2}$, $p=0.0004$ ) and was comparable with that of all GDM cases $\left(30.6 \pm 1.3 \mathrm{~kg} / \mathrm{m}^{2}\right.$; Table 1$)$. Immunoblotting revealed there to be no significant change in ER stress markers p-eIF2 $\alpha$ and GRP78 in the overweight/obese women (ESM Fig. 2a, b). However, the expression of XBP-1, which was increased in the GDM placentas, was significantly reduced (ESM Fig. 2b). Additionally, there was no correlation between the p-eIF $2 \alpha$ level in the placentas and maternal BMI in GDM (ESM Fig. 2c). To conclude, these results exclude the possibility of the increased ER stress in GDM placenta arising from maternal obesity.

High glucose does not directly activate ER stress in trophoblast-like cells To elucidate whether the placental ER stress observed in GDM pregnancies is the result of maternal hyperglycaemia, an in vitro model using trophoblast-like cells treated with high concentrations of glucose was introduced. As ER stress was observed solely in the syncytiotrophoblast, BeWo-NG cells were treated with forskolin A to induce differentiation into syncytial masses prior to experimentation.

BeWo-NG cells adapted to a $5.5 \mathrm{mmol} / \mathrm{l}$ physiological glucose concentration were challenged with 10 and $20 \mathrm{mmol} / 1$ glucose for $24 \mathrm{~h}$. The high glucose treatments induced an over sixfold elevation of p-eIF2 $\alpha$ (Fig. 2a). However, other ER stress markers, GRP78, GRP94 and XBP-1(FL), and the ER 
Table 1 Clinical characteristics of the participants according to study group

\begin{tabular}{|c|c|c|c|c|c|}
\hline Characteristic & Control $1(n=10)$ & $\operatorname{GDM}(n=11)$ & Control $2(n=8)$ & $\begin{array}{l}\text { Non-GDM } \\
\text { overweight/obese } \\
(n=7)\end{array}$ & $\begin{array}{l}p \text { value } \\
\text { (ANOVA) }\end{array}$ \\
\hline Maternal age (years) & $32 \pm 1.5$ & $34.3 \pm 1.4$ & $33.5 \pm 2.4$ & $33.7 \pm 0.5$ & NS \\
\hline Gestational age (weeks) & $38.1 \pm 0.2$ & $38.9 \pm 0.4$ & $38.8 \pm 0.2$ & $39 \pm 0.2^{\mathrm{b}}$ & 0.013 \\
\hline Birthweight (g) & $3582 \pm 104$ & $4195 \pm 239$ & $3595 \pm 136$ & $3830 \pm 181$ & NS \\
\hline Placental weight $(\mathrm{g})$ & $647 \pm 52$ & $767 \pm 74$ & $661 \pm 62$ & $680 \pm 109$ & NS \\
\hline Pre-pregnancy BMI (kg/m²) & $22.8 \pm 1.2$ & $30.6 \pm 1.3^{\mathrm{a}}$ & $21 \pm 0.2$ & $29 \pm 1.0^{\mathrm{b}}$ & 0.0004 \\
\hline \multicolumn{6}{|c|}{ Rate of pre-pregnancy overweight/obesity (\%) } \\
\hline $\mathrm{BMI} \geq 25 \mathrm{~kg} / \mathrm{m}^{2}$ & 30 & 72.7 & 0 & 100 & \\
\hline $\mathrm{BMI} \geq 30 \mathrm{~kg} / \mathrm{m}^{2}$ & 0 & 36.3 & 0 & 28.6 & \\
\hline Delivery BMI $\left(\mathrm{kg} / \mathrm{m}^{2}\right)$ & $29.1 \pm 1.2$ & $34.7 \pm 0.9^{\mathrm{b}}$ & $27.3 \pm 1.1$ & $33.1 \pm 1.2$ & 0.0065 \\
\hline \multicolumn{6}{|c|}{ Capillary $\mathrm{HbA}_{1 \mathrm{c}}$ (late third trimester) } \\
\hline$(\%)$ & $5^{\mathrm{c}}$ & $5.86 \pm 0.55$ & $5^{\mathrm{c}}$ & - & \\
\hline$(\mathrm{mmol} / \mathrm{mol})$ & $31^{\mathrm{c}}$ & $40.64 \pm 5.85$ & $31^{\mathrm{c}}$ & & \\
\hline \multicolumn{6}{|c|}{ Intervention during GDM pregnancy $(n)$} \\
\hline Insulin + diet & - & 5 & - & - & \\
\hline Diet & - & 6 & - & - & \\
\hline
\end{tabular}

Values are expressed as mean \pm SEM, unless stated otherwise

The 'Control 1' cohort is the initial normoglycaemic control group, containing 30\% overweight/obese women with a pre-pregnancy BMI $>25$. 'Control 2 ' is a second normoglycaemic control group of non-obese women with a pre-pregnancy BMI $<25$

'Overweight/obese GDM' comprise of a subset of 'GDM' participants

Differences were tested using the non-parametric Kruskal-Wallis test, followed by Dunn's multiple comparisons test

${ }^{\text {a }}$ Statistically significant compared with Control 1

${ }^{\mathrm{b}}$ Statistically significant compared with Control 2

${ }^{\mathrm{c}} \mathrm{HbA}_{1 \mathrm{c}}$ was not measured in normal pregnancies; reference values during the third trimester were those measured by Neilsen et al [21]

residential proteins protein disulfide isomerase (PDI) and calreticulin, appeared to be unchanged (Fig. 2b).

A change of the $\mathrm{pH}$ indicator (Phenol Red) in the modified DMEM/F12 medium suggested that the high glucose concentrations caused metabolic acidosis. Indeed, while the mean $\mathrm{pH}$ of the $5.5 \mathrm{mmol} / 1$ glucose medium dropped from 7.0 to 6.8 after $24 \mathrm{~h}$, in both the 10 and $20 \mathrm{mmol} / \mathrm{l}$ glucose media it was reduced to $\sim 6.2$ (Fig. 2c). These reductions in $\mathrm{pH}$ were partially a result of lactate accumulation as there was a $\sim 23 \%$ and $\sim 15 \%$ increase in lactate in the media containing 10 and $20 \mathrm{mmol} / 1$ glucose, respectively (Fig. 2d).

To determine whether metabolic acidosis, per se, can induce ER stress, the volume of the medium was increased from 2 to $3 \mathrm{ml}$ to dilute the metabolites. As a consequence, the $\mathrm{pH}$ of the media containing 10 and $20 \mathrm{mmol} / \mathrm{l}$ glucose was partially restored to $\sim 6.6$ (Fig. 2 c). Phosphorylation of eIF $2 \alpha$ was greatly decreased (Fig. 2b), while levels of all other ER stress markers and residential proteins remained unchanged. To summarise, these results suggest that high glucose is unlikely to be a direct inducer of ER stress.

High glucose-induced acidosis triggers mild ER stress in trophoblast-like cells To further explore the potential role of metabolic acidosis in activation of ER stress in BeWo-NG cells, two approaches were introduced. First, an extra $15 \mathrm{mmol} / \mathrm{l}$ of sodium bicarbonate $\left(\mathrm{NaHCO}_{3}\right)$ was added to the culture medium, raising the concentration from 14 to $29 \mathrm{mmol} / \mathrm{l}$, to increase its buffering capacity. This caused the basal $\mathrm{pH}$ value to rise to $\sim 7.5$ (Fig. 2c). After incubation for $24 \mathrm{~h}$ the $\mathrm{pH}$ of all the media with added $\mathrm{NaHCO}_{3}$ were significantly higher than the $\mathrm{pH}$ of media without the added $\mathrm{NaHCO}_{3}$ (Fig. 2c). In the 10 and $20 \mathrm{mmol} / \mathrm{l}$ glucose media, the values were $\sim 7.0$. Restoration of the $\mathrm{pH}$ reduced $\mathrm{p}$-eIF $2 \alpha$ by threefold (Fig. 2f), while levels of other ER stress markers and residential proteins appeared to remain constant (Fig. 2e).

Next, BeWo-NG cells were exposed for $1-6 \mathrm{~h}$ to media containing $5.5 \mathrm{mmol} / \mathrm{l}$ glucose with different acidities, ranging from $\mathrm{pH} 5.5$ to 7.0. Culture for up to $6 \mathrm{~h}$ did not alter the $\mathrm{pH}$ values in the media, eliminating the possibility of any effect from accumulating metabolites (data not shown). Media with a pH higher than 6.5 did not induce ER stress (Fig. 2g). There was a time-dependent increase in p-eIF $2 \alpha$ in medium with a $\mathrm{pH}$ of 6.0 , but other ER stress markers remained constant. In medium of $\mathrm{pH} 5.5$, $\mathrm{p}$-eIF $2 \alpha$ was increased strongly after only $3 \mathrm{~h}$, and the level of XBP-1(FL) rose after $6 \mathrm{~h}$ (Fig. 2g). Phase- 
Fig. 1 Low-grade ER stress in the GDM placentas. (a) Electron micrographs showing dilated ER cisternae (arrows) in the syncytiotrophoblast (SynT) but not in the cytotrophoblast (CT) or endothelial cells (EC). FV, fetal vessel. Magnification $\times 5000$. (b) Representative blots of p-eIF $2 \alpha$, eIF2 $\alpha$, ATF6 $\alpha$, unspliced XBP-1 (XBP-1(FL)), GRP94 and GRP78. $\beta$-actin was used as loading control. (c) Quantification of the band intensity from (b). The $y$-axis shows the relative level of phosphorylated or total protein. Phosphorylation status of eIF $2 \alpha$ is presented as the ratio between phosphorylated and total protein. All protein levels are normalised to $\beta$-actin. Data are presented as mean \pm SEM, $n=10$ or $11 ; * p<0.05 ; * * p<0.01 \mathrm{vs}$ control. (d, e) Correlation between $\mathrm{HbA}_{1 \mathrm{c}}$ and (d) $\mathrm{p}$-eIF2 $\alpha$ and (e) XBP-1(FL). In (d, e), the concentration of $\mathrm{HbA}_{1 \mathrm{c}}$ was plotted against relative ratio of p-eIF $2 \alpha$ or XBP-1(FL) and a linear regression line added
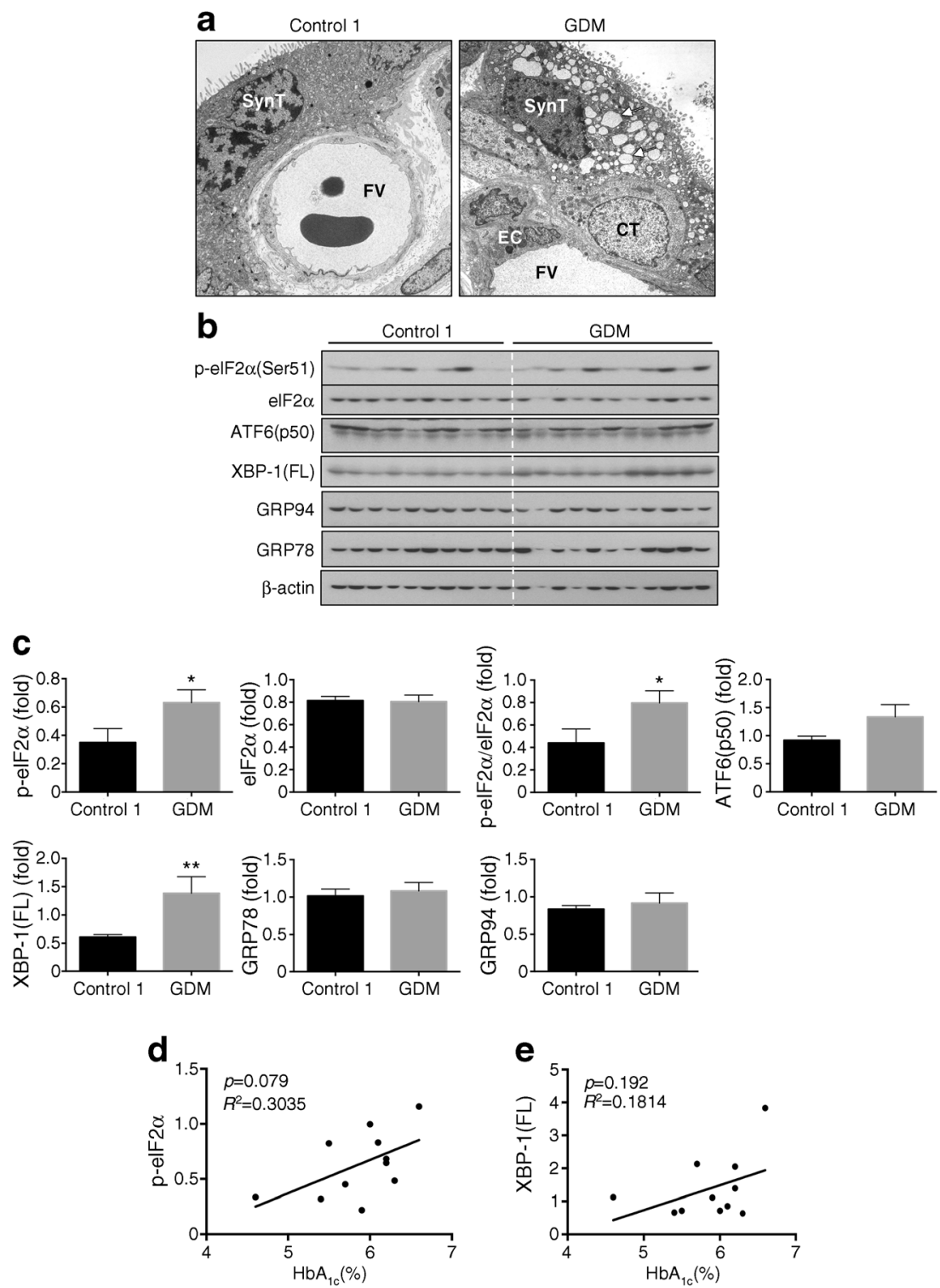

contrast microscopy examination revealed condensed nuclei and loss of membrane integrity; potential signs of necrosis (data not shown). A marked reduction of the ER residential proteins PDI and calreticulin (Fig. 2g), and of the cytosolic protein p38 kinase (ESM Fig. 3a), confirmed that the cells were losing both ER and plasma membrane integrity under these conditions.

To summarise, these findings suggest that exposure to a low $\mathrm{pH}$ can alter ER homeostasis, thereby activating the UPR.

ER molecular chaperones and antioxidants suppress high glucose-induced ER stresses Chemical chaperones, including 4-phenylbutyrate (4-PBA) and tauroursodeoxycholic acid (TUDCA), have been widely demonstrated to be effective in reducing ER stress [23], while antioxidants, such as vitamins $\mathrm{C}$ and E, suppress oxidative stress in placental explants [24].
Therefore, we investigated the effects of chemical chaperones and antioxidants in the suppression of high glucose-induced ER stress. Both chemical chaperones and antioxidants were effective in reducing phosphorylation of eIF2 $\alpha$ (Fig. 3a, b), while all other ER stress markers and residential proteins remained unchanged (Fig. 3a). Surprisingly, vitamins, but not chemical chaperones, significantly restored the $\mathrm{pH}$ of the normal media to $\sim 6.7$ and reduced lactate accumulation by over $50 \%$ in the presence of 10 and $20 \mathrm{mmol} / 1$ glucose (Fig. 3c, d). Vitamin C or vitamin E alone suppressed high glucose-induced ER stress and restored the $\mathrm{pH}$, but were not as effective when combined (data not shown). These results reveal potential beneficial effects of both chemical chaperones and vitamins $\mathrm{C}$ and $\mathrm{E}$ in reducing ER stress. Additionally, not only can the vitamins suppress the ER stress induced by high glucose but they may also be used to prevent hyperglycaemiainduced acidosis. 
a

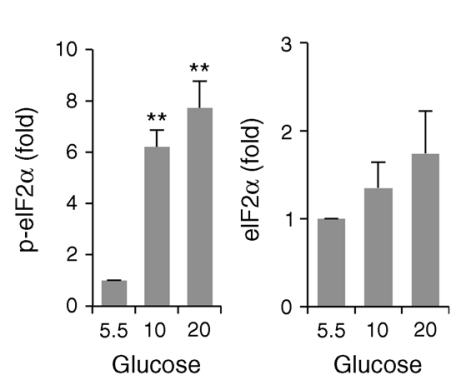

C

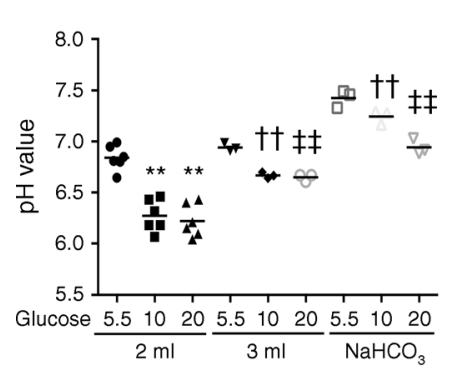

b

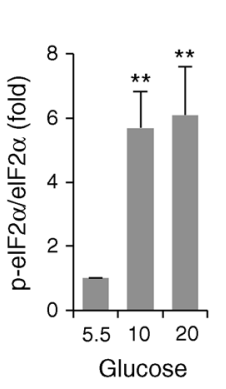

d

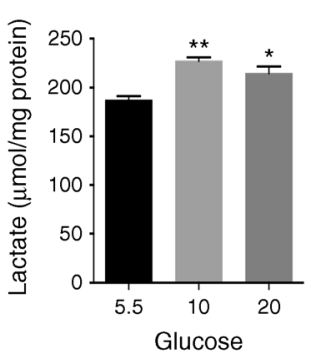

\begin{tabular}{ll|l|l|l|l|l|} 
Glucose & 5.5 & 10 & 20 & 5.5 & 10 & 20 \\
\hline
\end{tabular}

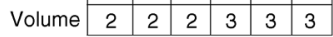

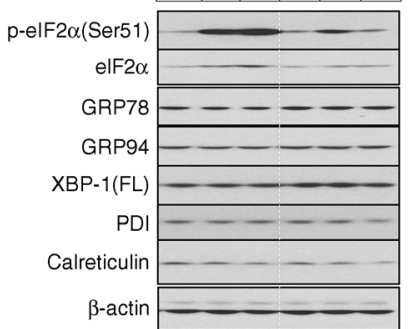

e

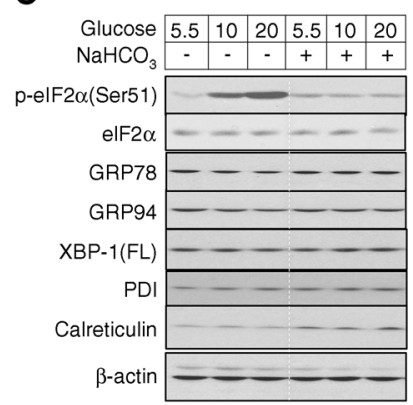

f
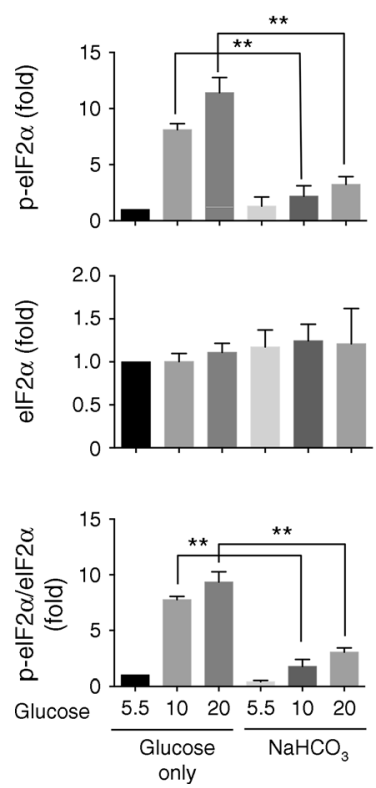

Fig. 2 ER stress induced by high glucose is mediated by metabolic acidosis. BeWo-NG cells were cultured in serum-free media containing $5.5,10$ and $20 \mathrm{mmol} / \mathrm{l}$ glucose in combination with various experimental conditions for $24 \mathrm{~h}$. ER stress markers were measured by western blotting, with $\beta$-actin or Ponceau S staining as loading control. (a) Phosphorylation of eIF $2 \alpha$ under different glucose concentrations $(\mathrm{mmol} / \mathrm{l})$. The $y$-axis shows the relative level of $\mathrm{p}$-eIF $2 \alpha$, eIF $2 \alpha$ and the ratio of p-eIF $2 \alpha / \mathrm{eIF} 2 \alpha .{ }^{*} p<<0.01$ vs $5.5 \mathrm{mmol} / 1$ glucose. (b) Representative blots showing effect of changing medium volume on phosphorylation of eIF $2 \alpha$. Cells were treated with different glucose concentrations (mmol/l) in $2 \mathrm{ml}$ (control) or $3 \mathrm{ml}$ incubation volume. (c) Effect of changing medium volume and buffering capacity on $\mathrm{pH}$ induced by high glucose $(10$ or $20 \mathrm{mmol} / \mathrm{l}) .{ }^{*} p<0.01$ vs $5.5 \mathrm{mmol} / 1$ glucose within the $2 \mathrm{ml}$ glucose-only control group; ${ }^{\dagger \dagger} p<0.01$ vs $10 \mathrm{mmol} / \mathrm{l}$ glucose in the $2 \mathrm{ml}$ glucose-only control group; ${ }^{+1} p<0.01$ vs $20 \mathrm{mmol} / 1$ glucose in the $2 \mathrm{ml}$ glucose-only control group. (d) Lactate production in high glucose medium. ${ }^{*} p<0.05$ and ${ }^{*} p p<0.01$ vs $5.5 \mathrm{mmol} / 1$ glucose. (e) Representative western blots showing phosphorylation of eIF $2 \alpha$ in relation to medium buffering capacity. Cells were cultured with different glucose concentrations $(\mathrm{mmol} / \mathrm{l})$ in the presence or absence of additional $\mathrm{NaHCO}_{3}(15 \mathrm{mmol} / \mathrm{l})$ for $24 \mathrm{~h}$. (f) Quantification of p-eIF2 $\alpha$ with or without $\mathrm{NaHCO}_{3}$. The $y$-axis shows the relative level of p-eIF $2 \alpha$ and eIF $2 \alpha$ and the ratio of $\mathrm{p}$-eIF $2 \alpha / \mathrm{eIF} 2 \alpha .{ }^{* *} p<0.01$ for presence vs absence of $\mathrm{NaHCO}_{3}$ at the same glucose concentration. (g) Effect of acidified culture media on induction of ER stress. The $\mathrm{pH}$ of the culture medium containing $5.5 \mathrm{mmol} / 1$ glucose was adjusted to 7, 6.5, 6 and 5.5, and the BeWo-NG cells were exposed to these media for 1,3 or $6 \mathrm{~h}$. Data are presented as mean \pm SEM or as immunoblot images, $n=3-6$ 
Fig. 3 Both chemical chaperones and antioxidants effectively suppress high glucose-induced ER stress, but only antioxidants reduce the degree of metabolic acidosis. BeWo-NG cells were treated with different

concentrations of glucose in the presence of either chemical chaperones, 4-PBA $(500 \mu \mathrm{mol} / \mathrm{l})$ and TUDCA $(250 \mu \mathrm{mol} / \mathrm{l})$, or vitamin $C$ (Vit C; $500 \mu \mathrm{mol} / \mathrm{l}$ ) or vitamin $\mathrm{E}$ (Vit E; $500 \mu \mathrm{mol} / \mathrm{l}$ ) for $24 \mathrm{~h}$. (a) Levels of ER stress markers were determined by western blotting. $\beta$-actin was used as loading control. (b) Phosphorylation status is presented as the ratio between phosphorylated and total protein. Data are presented as mean \pm SEM, $n=3$. The $y$-axis shows the relative level of p-eIF $2 \alpha$ eIF $2 \alpha$ or the ratio of p-eIF $2 \alpha /$ eIF $2 \alpha$. (c) $\mathrm{pH}$ of the culture media after the experiment. (d) Effect of vitamins on high glucose-induced lactate production. Data are presented as median, $n=3-6$. ${ }^{\dagger} p<0.05$ and ${ }^{\dagger \dagger} p<0.01$ vs $10 \mathrm{mmol} / \mathrm{l}$ glucose in the glucoseonly control group; ${ }^{\star} p<0.05$ and ${ }^{\star} p<0.01$ vs $20 \mathrm{mmol} / 1$ glucose in the glucose-only control group

a

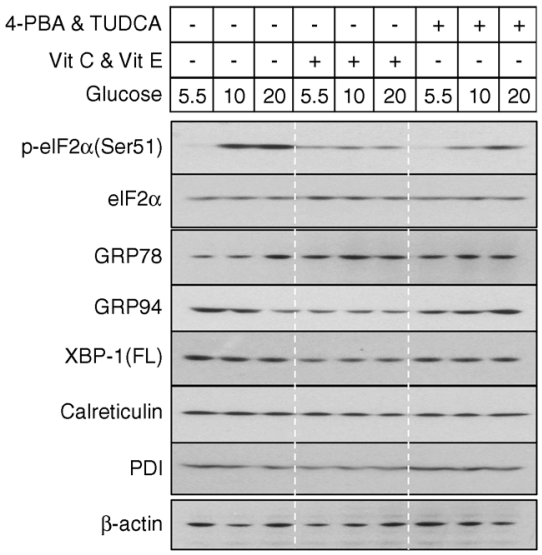

b

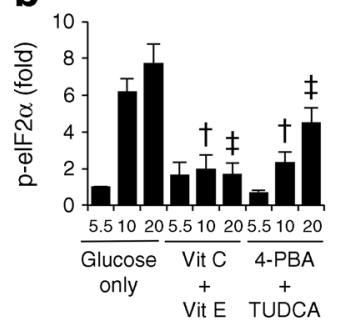

C

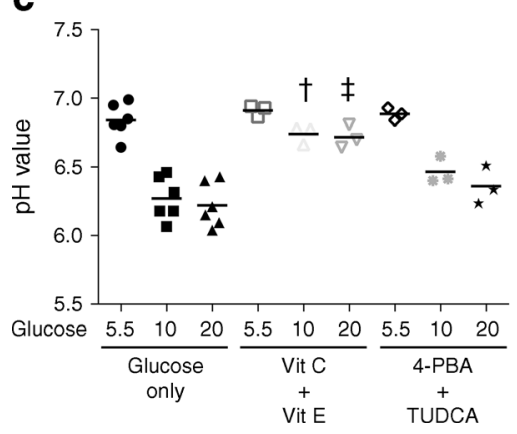

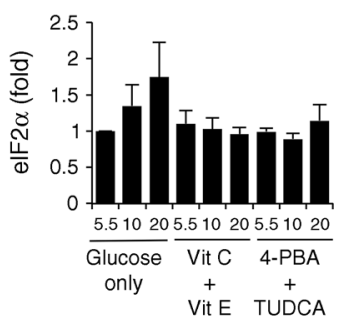

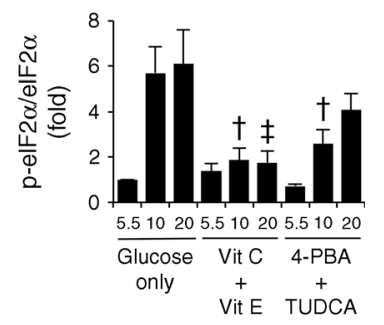

d

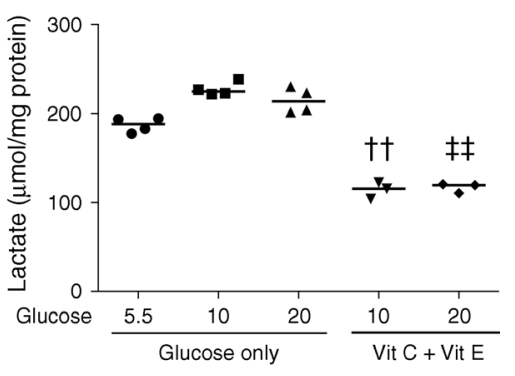

\section{Discussion}

In this study, we provide the first evidence for the existence of placental ER stress in women with established GDM, as demonstrated by dilatation of ER cisternae in the syncytiotrophoblast and increased p-eIF $2 \alpha$ and unspliced XBP-1 protein. Evidence for activation of the IRE1 $\alpha$ arm remains elusive because of inconsistent signals from the downstream effectors, with no splicing of XBP-1, but potential activation of the TNF receptor-associated factor 2 (TRAF2)-c-Jun N-terminal kinase (JNK) pathway (ESM Fig. 4). To conclude, the results suggest that placental ER stress in GDM is mild compared with that observed in pregnancies complicated by fetal growth restriction and earlyonset pre-eclampsia $[18,25]$. It must be remembered, however, that the GDM placentas studied came from women whose glucose levels were well-controlled, as evidenced by mean $\mathrm{HbA}_{1 \mathrm{c}}$ levels which were only just outside the normal range.
The severity of placental pathology in individuals with diabetes is generally related to the quality of glucose control [26].

To test whether elevated glucose concentrations per se are able to induce ER stress, we developed a new trophoblast-like cell line adapted to physiological glucose concentrations, BeWo-NG. Use of these cells revealed that high glucose concentrations induce ER stress in vitro, most likely through metabolic acidosis. Activation of the UPR was limited to the PERK signalling arm. Severe acidosis induces ER stress in other cell types [27]. Although the mechanisms are elusive, the activity of $\mathrm{Ca}^{2+}$-ATPases is susceptible to acidosis and there is a $\mathrm{pH}$-dependent $\mathrm{Ca}^{2+}$ efflux from the intracellular storage compartments. Acidification of the medium (from pH 7.0 to 6.5) causes release of $\mathrm{Ca}^{2+}$ from the ER and loss of ER homeostasis [28], activating the UPR. Lactic acid has been demonstrated to induce phosphorylation of eIF $2 \alpha$ in cancer cells, possibly through this mechanism [29]. In GDM, excessive maternal blood glucose could facilitate 
overproduction of lactate in the placenta, resulting in metabolic acidosis. Unlike many organs, in which lactate production is usually under hypoxic conditions, the placenta synthesises considerable quantities of lactate under aerobic conditions [30].

The human placenta expresses all five isozymes of lactate dehydrogenase, which catalyses the inter-conversion of lactate and pyruvate in the glycolytic pathway [31]. The activity of only one of the five isozymes is increased in trophoblast cells upon hypoxia [30], suggesting that the majority of the placental isozymes may facilitate lactate production aerobically. The amount of lactate produced by the placenta is directly proportional to the maternal glucose concentration, as elevation of the glucose concentration from 4.2 to $10.9 \mathrm{mmol} / \mathrm{l}$ during placental perfusion in vitro induced a fourfold increase in lactate production. However, raising the glucose concentration further had no additional effect [32], consistent with our observation of no change in the $\mathrm{pH}$ value of media containing 10 or $20 \mathrm{mmol} / \mathrm{l}$ glucose. Unfortunately, data on placental lactate production in vivo in GDM patients are not available. A study by Taricco et al, using indirect measures, reported a $23 \%$ increase of lactate concentration in the umbilical vein in GDM pregnancies [33]. Hence, the placenta is likely producing more lactate in GDM and transporting it to the fetus for metabolism.

An alternative explanation is that the placental ER stress reflects the maternal pro-inflammatory environment associated with obesity [34], a potentially confounding variable as our participants were not matched for pre-pregnancy BMI. However, placentas from normoglycaemic obese women did not show ER stress. Furthermore, adding palmitic acid to BeWo-NG cells during a high glucose challenge did not exacerbate the ER stress (ESM Fig. 2a, b, d), indicating that high levels of fatty acids are unlikely to be a causative factor. Finally, there was no correlation between the level of peIF $2 \alpha$ and the BMI of the women at the time of delivery (ESM Fig. 2c). Together, these results suggest that obesity is unlikely to be the cause of the placental ER stress observed in GDM.

Oxidative stress is also a strong inducer of ER stress in the trophoblast [35]. However, the existence of oxidative stress in GDM placentas remains contentious as both increased and unchanged stress have been reported [36, 37]. This may be due to differences in the percentages of women under dietary control $(85 \%$ vs $53 \%)$ and insulin therapy ( $15 \%$ vs $47 \%)$. Nevertheless, the GDM placentas used in this study (54\% of which were from those under dietary control) showed only a mild level of oxidative stress as indicated by activation of JNKs without significant changes in p38 kinase phosphorylation and heat shock proteins (ESM Fig. 4). We speculate that placental ER and oxidative stress may occur to a greater extent in GDM pregnancies with more severe metabolic acidosis. Indeed, treating BeWo-NG cells with low-pH media strongly activated the oxidative stress marker p38 kinase phosphorylation (ESM Fig. 3a), similar to treatment with high glucose concentrations (ESM Fig. 3b). These results suggest that the oxidative stress observed in GDM placentas may be triggered at least in part by placental metabolic acidosis. Further studies are required to confirm this hypothesis.

Finally, we demonstrated the potential use of chemical ER chaperones and antioxidant vitamins as therapeutic interventions to prevent glucose-induced placental ER stress. Chemical chaperones had a similar efficacy to that of antioxidants in the suppression of ER stress at a glucose concentration of $10 \mathrm{mmol} / \mathrm{l}$, but the chemical chaperones lost their beneficial effects at a higher concentration of $20 \mathrm{mmol} / \mathrm{l}$ (Fig. 3a, b). The exact mechanisms by which vitamins $\mathrm{C}$ and $\mathrm{E}$ restore $\mathrm{pH}$ at high glucose concentrations are not known. However, they are unlikely to be related to their antioxidant properties, as other antioxidants (edaravone and $N$-acetylL-cysteine) had no effect (data not shown). Nonetheless, both vitamin $\mathrm{C}$ and vitamin $\mathrm{E}$ protect muscle cells from mitochondrial damage, including membrane rupture, during exhaustive exercise, which is accompanied by lactate accumulation [38]. Therefore, the vitamins may maintain mitochondrial integrity and function during metabolic acidosis, thereby reducing anaerobic lactate production. Indeed, our data in Fig. 3d showing inhibition of lactate production support this speculation.

These results provide new insight into the potential use of ER chaperones as therapeutic agents in diabetic pregnancies. Additionally, vitamins $\mathrm{C}$ and $\mathrm{E}$ could be administered as health supplements in conjunction with both dietary and insulin control to mitigate the adverse effects of metabolic acidosis on the placenta, thereby improving fetal wellbeing. Furthermore, in a mouse model of diabetes, hyperglycaemiainduced ER stress mediated embryopathy can be ameliorated through administration of 4-PBA [39].

Acknowledgements The authors thank L. Levy at The Research Center for Obstetrics and Gynecology, Oslo University Hospital (led by ACS), for excellent participant recruitment as well as technical biobank and laboratory assistance.

Funding This study was supported by a grant from the Wellcome Trust (084804/2/08/Z). TE-B was supported by a Newton Advanced Fellowship awarded to TE-B and GJB from the Academy of Medical Sciences and by the Fundação Carlos Chagas Filho de Amparo à Pesquisa do Estado do Rio de Janeiro.

Duality of interest The authors declare that there is no conflict of interest associated with this manuscript.

Contribution statement HWY, ACS and GJB conceived and designed the study. PA-K acquired clinical data and collected tissue samples, and HWY, MG, CJPJ and TE-B acquired experimental data. HWY, PA-K, MG, CJPJ, TE-B, ACS and GJB analysed and interpreted the data. HWY, $\mathrm{P}-\mathrm{AK}, \mathrm{ACS}$ and GJB drafted the paper, and CJPJ, TE-B and MG revised it critically for intellectual content. All authors approved the final version to be published. HWY is responsible for the integrity of the work as a whole. 
Open Access This article is distributed under the terms of the Creative Commons Attribution 4.0 International License (http:// creativecommons.org/licenses/by/4.0/), which permits unrestricted use, distribution, and reproduction in any medium, provided you give appropriate credit to the original author(s) and the source, provide a link to the Creative Commons license, and indicate if changes were made.

\section{References}

1. Sacks DA, Hadden DR, Maresh M et al (2012) Frequency of gestational diabetes mellitus at collaborating centers based on IADPSG consensus panel-recommended criteria: the Hyperglycemia and Adverse Pregnancy Outcome (HAPO) Study. Diabetes Care 35: 526-528

2. Bryson CL, Ioannou GN, Rulyak SJ, Critchlow C (2003) Association between gestational diabetes and pregnancy-induced hypertension. Am J Epidemiol 158:1148-1153

3. Damm P (1998) Gestational diabetes mellitus and subsequent development of overt diabetes mellitus. Dan Med Bull 45:495-509

4. Hawdon JM (2011) Babies born after diabetes in pregnancy: what are the short- and long-term risks and how can we minimise them? Best Pract Res Clin Obstet Gynaecol 25:91-104

5. Clausen TD, Mathiesen ER, Hansen T et al (2009) Overweight and the metabolic syndrome in adult offspring of women with diettreated gestational diabetes mellitus or type 1 diabetes. J Clin Endocrinol Metab 94:2464-2470

6. Wright CS, Rifas-Shiman SL, Rich-Edwards JW, Taveras EM, Gillman MW, Oken E (2009) Intrauterine exposure to gestational diabetes, child adiposity, and blood pressure. Am J Hypertens 22: 215-220

7. Newbern D, Freemark M (2011) Placental hormones and the control of maternal metabolism and fetal growth. Curr Opin Endocrinol Diabetes Obes 18:409-416

8. Brelje TC, Scharp DW, Lacy PE et al (1993) Effect of homologous placental lactogens, prolactins, and growth hormones on islet B-cell division and insulin secretion in rat, mouse, and human islets: implication for placental lactogen regulation of islet function during pregnancy. Endocrinology 132:879-887

9. Barbour LA, Shao J, Qiao L et al (2002) Human placental growth hormone causes severe insulin resistance in transgenic mice. Am J Obstet Gynecol 186:512-517

10. Handwerger S, Freemark M (2000) The roles of placental growth hormone and placental lactogen in the regulation of human fetal growth and development. J Pediatr Endocrinol Metab 13:343-356

11. Ashworth CJ, Hoggard N, Thomas L, Mercer JG, Wallace JM, Lea RG (2000) Placental leptin. Rev Reprod 5:18-24

12. Chen J, Tan B, Karteris E et al (2006) Secretion of adiponectin by human placenta: differential modulation of adiponectin and its receptors by cytokines. Diabetologia 49:1292-1302

13. Ron D, Walter P (2007) Signal integration in the endoplasmic reticulum unfolded protein response. Nat Rev Mol Cell Biol 8:519529

14. Cao SS, Kaufman RJ (2013) Targeting endoplasmic reticulum stress in metabolic disease. Expert Opin Ther Targets 17:437-448

15. Scheuner D, Vander Mierde D, Song B et al (2005) Control of mRNA translation preserves endoplasmic reticulum function in beta cells and maintains glucose homeostasis. Nat Med 11:757-764

16. Buchanan TA, Xiang AH, Page KA (2012) Gestational diabetes mellitus: risks and management during and after pregnancy. Nat Rev Endocrinol 8:639-649

17. Kuhl C, Hornnes PJ (1986) Endocrine pancreatic function in women with gestational diabetes. Acta Endocrinol Suppl (Copenh) 277: $19-23$
18. Yung HW, Calabrese S, Hynx D et al (2008) Evidence of placental translation inhibition and endoplasmic reticulum stress in the etiology of human intrauterine growth restriction. Am J Pathol 173:451462

19. Yung HW, Cox M, Tissot van Patot M, Burton GJ (2012) Evidence of endoplasmic reticulum stress and protein synthesis inhibition in the placenta of non-native women at high altitude. FASEB J 26: 1970-1981

20. Lee CQE, Gardner L, Turco M et al (2016) What is trophoblast? A combination of criteria define human first-trimester trophoblast. Stem Cell Rep 6:257-272

21. Hamilton SD, Pardue HL (1984) Quantitation of lactate by a kinetic method with an extended range of linearity and low dependence on experimental variables. Clin Chem 30:226-229

22. Nielsen LR, Ekbom P, Damm P et al (2004) HbA1c levels are significantly lower in early and late pregnancy. Diabetes Care 27: 1200-1201

23. Welch WJ, Brown CR (1996) Influence of molecular and chemical chaperones on protein folding. Cell Stress Chaperones 1:109-115

24. Cindrova-Davies T, Spasic-Boskovic O, Jauniaux E, CharnockJones DS, Burton GJ (2007) Nuclear factor-kappa B, p38, and stress-activated protein kinase mitogen-activated protein kinase signaling pathways regulate proinflammatory cytokines and apoptosis in human placental explants in response to oxidative stress: effects of antioxidant vitamins. Am J Pathol 170: $1511-1520$

25. Yung HW, Atkinson D, Campion-Smith T, Olovsson M, CharnockJones DS, Burton GJ (2014) Differential activation of placental unfolded protein response pathways implies heterogeneity in causation of early- and late-onset pre-eclampsia. J Pathol 234:262-276

26. Starikov R, Inman K, Chen K et al (2014) Comparison of placental findings in type 1 and type 2 diabetic pregnancies. Placenta 35: 1001-1006

27. Aoyama K, Burns DM, Suh SW et al (2005) Acidosis causes endoplasmic reticulum stress and caspase-12-mediated astrocyte death. J Cereb Blood Flow Metab 25:358-370

28. Wolosker H, Rocha JB, Engelender S, Panizzutti R, De Miranda J, de Meis L (1997) Sarco/endoplasmic reticulum Ca2+-ATPase isoforms: diverse responses to acidosis. Biochem J 321(Pt 2):545-550

29. Tang X, Lucas JE, Chen JL et al (2012) Functional interaction between responses to lactic acidosis and hypoxia regulates genomic transcriptional outputs. Cancer Res 72:491-502

30. Kay HH, Zhu S, Tsoi S (2007) Hypoxia and lactate production in trophoblast cells. Placenta 28:854-860

31. Van Bogaert EC, De Peretti E, Villee CA (1967) Electrophoretic studies of human placental dehydrogenases. Am J Obstet Gynecol 98:919-923

32. Hauguel S, Desmaizieres V, Challier JC (1986) Glucose uptake, utilization, and transfer by the human placenta as functions of maternal glucose concentration. Pediatr Res 20:269-273

33. Taricco E, Radaelli T, Rossi G et al (2009) Effects of gestational diabetes on fetal oxygen and glucose levels in vivo. BJOG 116: $1729-1735$

34. Pantham P, Aye IL, Powell TL (2015) Inflammation in maternal obesity and gestational diabetes mellitus. Placenta 36:709-715

35. Yung HW, Korolchuk S, Tolkovsky AM, Charnock-Jones DS, Burton GJ (2007) Endoplasmic reticulum stress exacerbates ischemia-reperfusion-induced apoptosis through attenuation of Akt protein synthesis in human choriocarcinoma cells. FASEB J 21:872-884

36. Biri A, Onan A, Devrim E, Babacan F, Kavutcu M, Durak I (2006) Oxidant status in maternal and cord plasma and placental tissue in gestational diabetes. Placenta 27:327-332 
37. Araujo JR, Ramalho C, Correia-Branco A et al (2013) A parallel increase in placental oxidative stress and antioxidant defenses occurs in pre-gestational type 1 but not gestational diabetes. Placenta 34:1095-1098

38. Rosa EF, Ribeiro RF, Pereira FM, Freymuller E, Aboulafia J, Nouailhetas VL (2009) Vitamin C and E supplementation prevents mitochondrial damage of ileum myocytes caused by intense and exhaustive exercise training. J Appl Physiol (1985) 107: $1532-1538$

39. Li X, Xu C, Yang P (2013) c-Jun NH2-terminal kinase 1/2 and endoplasmic reticulum stress as interdependent and reciprocal causation in diabetic embryopathy. Diabetes 62:599-608 